Our Nature (2008)6:30-37

\title{
Morphology and Morphometry of the Olfactory Rosette of a Teleostean Fish: Catla catla (Ham.)
}

\author{
K. Kumari \\ Ichthyology Research Laboratory, University Department of Zoology, T.M. Bhagalpur University, \\ Bhagalpur -812007 , India
}

Received: 28.02.2008, Accepted: 07.06.2008

\begin{abstract}
The morphological structure and morphology of the olfactory organs in a freshwater, aquatic breathing fish, Catla catla (Ham.) has been described. It consists of two nasal openings on each side of the head, the anterior and posterior nasal opening with a prominent nasal flap in between. A pair of olfactory rosettes is lodged in the depression called olfactory pits or olfactory chambers. The olfactory rosettes are oval, cup shaped structures. Each rosette bears a series of olfactory lamellae on each side of the median raphe. A single lamella is a flat, bifid tongue like structure. Measurements of the dimension of olfactory rosettes have been made and the data were analysed with respect to body weight using logarithmic transformations, $\mathrm{Y}=\mathrm{aw}^{\mathrm{b}}$. The total number of lamellae in the olfactory rosette increased with increase in body weight. With unit increase in body weight, the total number of lamellae increased by a power (b) of 0.2603 , while the total surface area of lamellae increased by power of (b) 0.636 . Both the parameters showed highly significant correlation coefficient i.e. $\mathrm{r}=0.9894 ; \mathrm{P}<0.001$ and $\mathrm{r}=0.95218 ; \mathrm{P}<0.001$ respectively.
\end{abstract}

Key words: Catla catla, Olfactory organ, Morphology, Morphometrics

\section{Introduction}

Fishes are usually provided with well developed paired olfactory rosettes lodged in the depression of olfactory pits or olfactory chambers in the head region. Externally, they are connected through the paired nasal or narial openings on the dorsal side of the head. The olfactory organs are of great biological importance as they help in detection of food and pery (Parker, 1922) and in other behaviours like parental care, recognition of sexes (Nordeny, 1971) and orientation etc. The olfactory organ of fishes shows wide range of variation depending upon various factors. Considerable information on the gross structure of olfactory organ is available from the works of Burne (1909), Teichmann (1954), Hasler (1957), Johnson and Brown (1962), Branson (1963), Gooding (1963), Pfeiffer (1963, 1964, 1965), Singh (1967), Kleerkoper (1969), Rana (1980) Sinha (1981, 1989), Datta et.al. $(1976,1982)$ etc. who have studied the morphology and anatomy of certain freshwater as well as marine fishes.

Although some earlier workers have tried to establish the relationship between the surface area of the olfactory rosette and the retinal area of the fish viz. Ojha and Kapoor (1973, 1974), Kapoor and Ojha (1973 a, b), Halama (1982) etc., yet information on their morphometrics i.e. relationship between olfactory lamellar area 
and the body weight of the fish is limited (Rana et.al., 1978; 1980).

Since morphological and the morphometric details of the olfactory rosette of Catla catla is not available, the present paper attempts to elucidate the same in an Indian major carp, Catla catla.

\section{Materials and methods}

Live specimens of Catla catla of different weight groups were collected from different ponds of Bhagalpur, Bihar, India. The fishes were anaesthetized in 1:1000 aqueous $\mathrm{Ms}_{222}$. Then the olfactory organs were fixed by injecting Bouin's fixative through the anterior nasal opening for some time (5 minutes) and then the head of the fish was immersed in the Bouin's fixative. Some fishes were similarly fixed in $10 \%$ formalin. The heads of the fixed fishes were dissected from the dorsal side under a stereoscope binocular microscope to examine the details of olfactory rosettes and their relationship with the brain of the fish.

For morphometric studies, the olfactory rosettes were carefully dissected out. Olfactory lamellae of the rosette were then removed one by one under the binocular microscope, and thus the number of lamellae in each rosette was counted. The separated lamellae were mounted in glycerin and viewed under the compound microscope. For measuring the surface area of a lamella, their shapes were outlined on a graph paper using Camera Lucida. Average surface area was calculated from the drawings of all the olfactory lamellae of a rosette belonging to different weight group of fishes. By multiplying the average bilateral surface area of an olfactory lamella with total number of olfactory lamellae in a rosette, the total olfactory surface area for each weight group of fish was obtained (Table 1).
The data obtained from the measurement of various parameters were analyzed on a computer by linear logarithmic transformation using the least squares regression method and have been shown in Table 2.

\section{Results and discussion}

Catla catla (Figure 1) belongs to the family Cyprinidae of the order Cypriniformes. It is a surface dwelling plankton feeder and an obligatory water breathing fish.

In Catla catla, the paired olfactory rosettes are situated on the anterodorsal aspect of the head in the depression of olfactory pits or olfactory chambers. Externally each pit has two separate openings, an anterior and a posterior nasal opening. The anterior opening is circular and remains wide open. The posterior outlet is of crescent shape. A prominent flap of skin, the nasal flap is present behind the anterior opening and covers the posterior opening (Figure 2). The olfactory rosettes are oval, cup-shaped structures, and are lodged in the depression of the olfactory pits. Each rosette remains connected with the olfactory bulbs at their bases. The paired olfactory bulbs are vase shaped structures (Figure 3). A deep bowl like space, the accessory nasal sac lies adjacent the olfactory rosette of each side and is connected to it through an opening (Figure 4). Similar accessory nasal sac has been reported by Kapoor and Ojha (1972) in Channa punctatus, Labeo rohita, and Cynoglossus oligolepis. Although Rana (1980) has observed the olfactory rosette in Catla catla but he has not mentioned the presence of any accessory nasal sacs. The present study reveals that the olfactory chamber communicates with accessory sac. Kyle (1899) suggested that accessory sacs are adaptations characteristic of fishes which have acquired a sedentary or semi- 
K. Kumari / Our Nature (2008) 6: 30-37

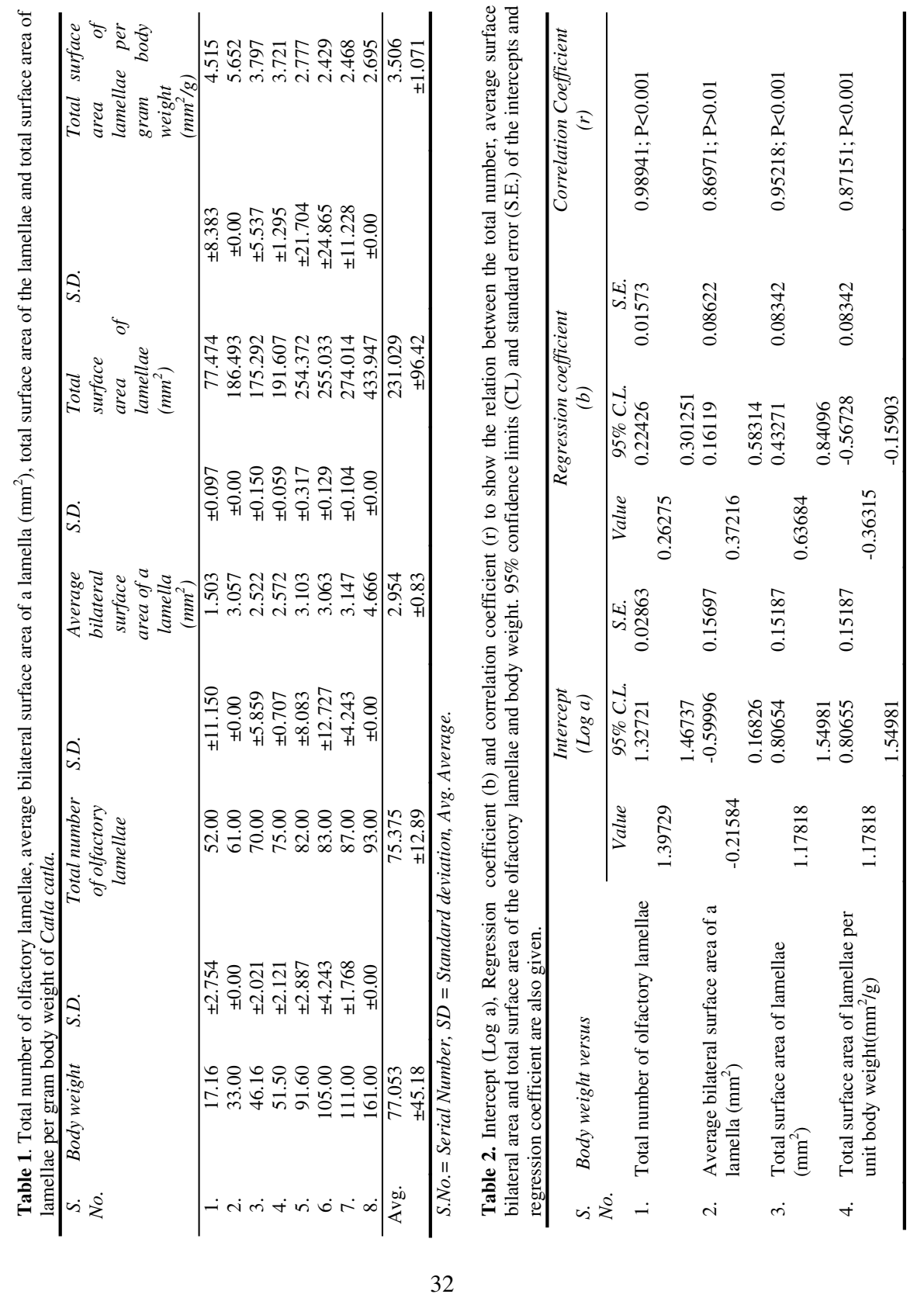




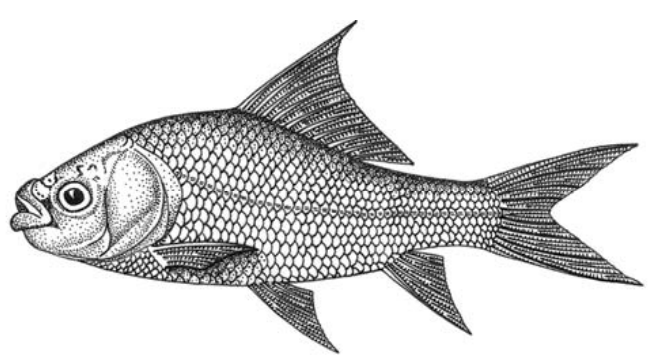

Fig. 1: Catla catla (Ham.)
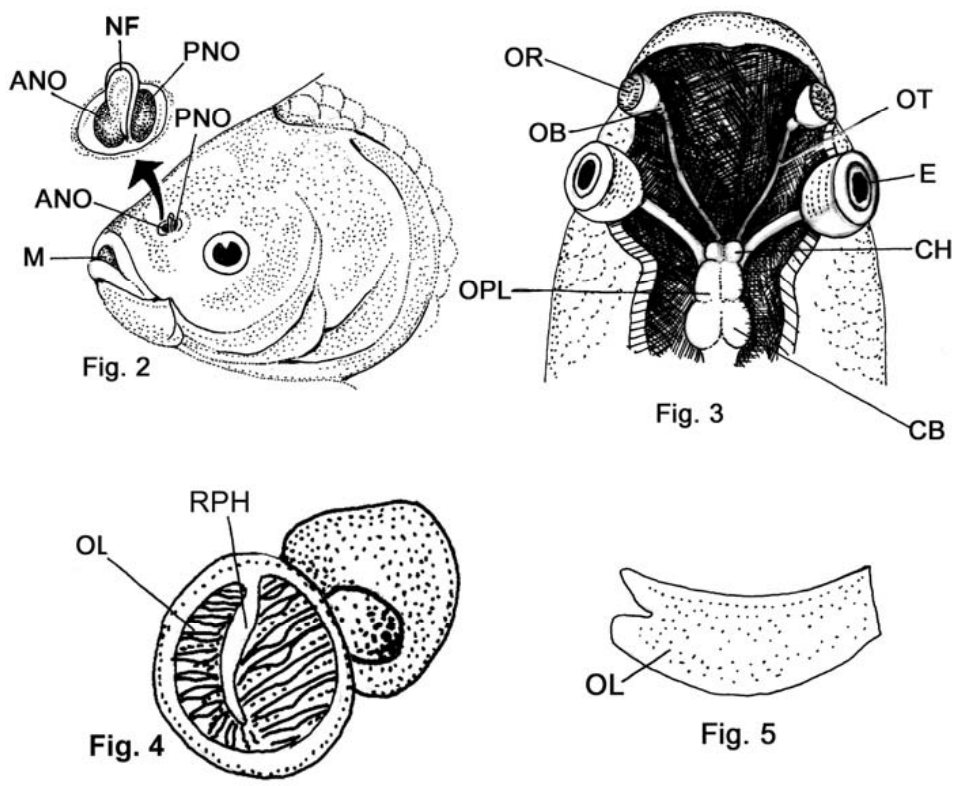

Fig. 5

Figure 1. Complete structure of the Catla catla. Figure 2. Lateral view of the head of Catla catla showing an anterior inlet and the posterior outlet, and the nasal flap. Figure 3. Antero-dorsal view of the head of Catla catla showing the olfactory organs and their relationship with the fore-brain. Figure 4. Complete structure of the olfactory, rosette of Catla catla showing its median raphe and the arrangement of the lamellae. Figure 5. Structure of a single olfactory lamella of Catla catla showing its flat bifid tongue like.

\section{LIST OF ABBREVIATION}

$\mathrm{NF}=$ NASAL FLAP, $\mathrm{ANO}=$ ANTERIOR NASAL OPENING, $\mathrm{PNO}=$ POSTERIOR NASAL OPENING,M= MOUTH, OR= OLFACTORY ROSETTE, OB= OPTIC LOBE, OT = OLFACTORY TRACT, E = EYE, CH= CEREBRAL HEMISPHERE, CB= CEREBELLUM, RPH= RAPHE, OL= OLFACTORY LAMELLA 
sedentary life. Burne (1909) challenged this view and regarded them as part of a general advance in structure occurring, at least in their most characteristic development, in families that have reached the highest allround development. But Catla catla is neither sedentary nor semi-sedentary. It is infact a surface dwelling and active fish. It is therefore, Burne's (1909) idea that the accessory sacs are advanced structures found in fishes that have reached the highest all round development seems more plausible. The median raphe of the olfactory rosettes are incomplete and terminates before $1 / 3^{\text {rd }}$ distance from the posterior end of the rosette. Each rosette of Catla catla bears two rows of olfactory lamella originating from the raphe (Figure 4). The lamellae in the middle of the rosette (on both sides) are the largest while they gradually reduce in size at their anterior and posterior ends. The lamellae are densely packed towards the anterior and posterior end of the rosette in comparision to the middle region. The interlamellar space between the two adjacent lamellae is very narrow. Each lamella is a flat bifid tongue like structure (Figure 5). Ojha and Kapoor (1973) observed similar type of lamella in another Indian major carp Labeo rohita belonging to the family Cyprinidae.

In Catla catla the rosette is oval in shape and can be classified under Bateson's (1889) rosette type-3, or Burne's (1909) rosette column-I, Teichmann (1954) rosette group-I. In Catla catla the eyes and olfactory organs are equally well developed. The overall structures of the olfactory rosette are very similar to another Indian major carp, Labeo rohita having similar systematic position.

\section{Morphometrics of the olfactory rosette}

The data obtained for the dimensions of the olfactory rosettes for eight weight groups of Catla catla have been summarized in Table 1. Similarly, the value obtained for intercept, regression coefficient (b) and correlation coefficient ( $r$ ) for different parameters of olfactory rosettes have been shown in Table 2. All dimensions of the olfactory rosettes increased with increase in body weight. However, olfactory surface area per gram body weight decreased with increase in body weight.

\section{Relationship between body weight and total number of olfactory lamellae}

Total number of olfactory lamellae in the two rosettes increased with increasing body weight. With gradual increase in body weight from $17.16 \mathrm{gm}$ to $161.00 \mathrm{gm}$ the total number of lamellae also increased from 52 to 93 respectively. A log-log plot of the

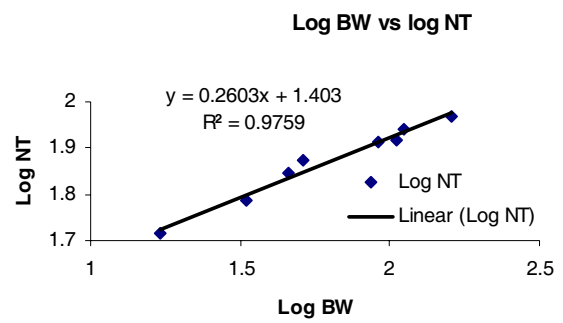

number of olfactory lamellae and body weight gave straight line, when the scores were fitted by the least square regression method. The slope value (b) was 0.263 , the intercept value (a) was 24.96286 and the correlation coefficient (r) was calculated to be 0.98941 . The correlation coefficient between the body weight and total number of lamella showed high degree of positive correlation. The two variables were highly significant $(r=0.98941 ; P<0.001)$. 


\section{Relationship between body weight and average bilateral surface area of a lamella}

The average bilateral surface area of a lamella increased from $1.503 \mathrm{~mm}^{2}$ to 4.667 $\mathrm{mm}^{2}$ as the body weight increased from $17.16 \mathrm{gm}$ to $161.0 \mathrm{gm}$. When the data for average bilateral surface area were plotted against body weight on log-log coordinates, a straight line was obtained with a slope value (b) of 0.372 . The correlation coefficient (r) was 0.86971 which did not show significant correlation $(\mathrm{r}=0.86971 ; \mathrm{P}$ $>0.01$ ).

Log BW vs log ABSA

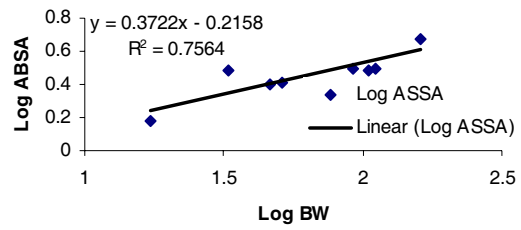

3. Relationship between body weight and total surface area of the lamellae (rosette)

The total surface area of lamellae also increased with increasing body weight of the fish. The log-log plot of total surface

Log BW vs $\log$ TSA

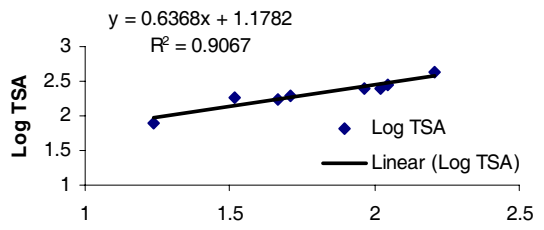

area and body weight gave a straight line with a slope value of (b) 0.637 and intercept (a) of 15.07234. The correlation coefficient $(\mathrm{r}=0.95218 ; \mathrm{P}<0.001)$ showing a highly significant positive correlation between the two variables.
4. Relationship between body weight and total surface area per unit body weight

The total surface area of the lamellae (i.e. olfactory rosette) per unit body weight showed a decreasing trend with increase in body weight. When the data for weight specific total surface area of lamellae were plotted against body weight on log-log coordinates, a straight line was obtained with a slope (b) value of -0.363 . The intercept (a) was calculated to be 15.07249 and the correlation coefficient (r) was 0.87151 . The two variables showed a highly significant negative correlation $(\mathrm{r}=$ $0.87151 ; \mathrm{P}<0.001)$.

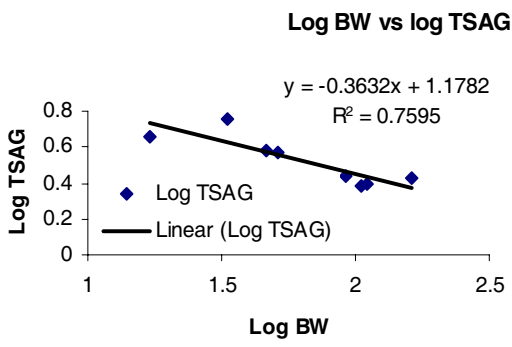

In Catla catla the total number of olfactory lamellae increased from 52 to 93 with an increase in body weight from 17.16 $\mathrm{gm}$ to $161.0 \mathrm{gm}$ showing an increase by a power (b) of 0.263 with unit increase in body weight. The lower value of regression was obviously due to the low increasing rate in the number of olfactory lamellae in higher weight group of fishes. It appears that the increase in the number of lamellae is a universal phenomenon in most of the fishes but the increase gradually slows down with increase in body weight. Whereas the increase in Channa gachua is faster ( $\mathrm{b}=$ 0.293) (Rana et.al., 1980), it is slightly less $(\mathrm{b}=0.209)$ in case of Channa punctatus (Rana et.al., 1978). 
The total surface area of the lamellae increases more rapidly $(b=0.637)$ than the total number of olfactory lamellae $(b=$ 0.263 ). This means that the higher weight group of fishes requires greater olfactory lamellar area for efficient olfaction which is achieved by increasing the surface area of the olfactory lamellae. The rate of increase in the total surface area of the lamellae was found to be higher both in C. gachua ( $\mathrm{b}=$ $0.808)$ and $C$. punctatus $(\mathrm{b}=0.750)$ in comparison to Catla catla i.e. $(\mathrm{b}=0.637)$. If Wunder's (1957) idea that the functional efficiency of the olfactory organ in a fish increases in a direct proportion to the increase in its epithelial surface is accepted, then the olfactory apparatus of Catla catla seems to be less efficient in comparision to the murrles.

However, to verify this, the number of receptor cells per unit area in the above fishes is to be studied.

\section{Acknowledgements}

The author is thankful to the University Grants Commission for the financial support in the form of Rajiv Gandhi National Fellowship No. F. 16 - 176 / 2006 (SA-II). The author is indebted to Prof. S.P. Roy, Head, Univ. Dept. of Zoology for the laboratory facilities and to Dr. T.K. Ghosh and Dr. P.K. Roy for their guidance and encouragement.

\section{References}

Bateson, W. 1889. The sense organs and perceptions of fishes, with remarks on the supply of bait. J. Marine Biol. Assoc. Lond. 1: 225-256.

Branson, B.A. 1963. The olfactory apparatus of Hybopsis gelida (Girard) and Hybopsis aestivalis (Girard). J. Morphol. 113: 215-229.
Burne, R.H. 1909. The anatomy of the olfactory organ of teleostean fishes. Proc. Zool. Soc. Lond. 2: 610-633.

Datta, N.C., A. Das and S. Deb 1982. Olfactory apparatus in two Indian Clupied fishes. Vest. cs. Spolec. Zool. 46: 1-4.

Datta, N.C., A.K. Saha and A. Das 1976. Investigation on the morphology of the olfactory apparatus of Anabas testudineus (Bloch). Ind.. J. Inland Fish. Soc. 8: 13-18.

Gooding, R.M. 1963. The olfactory organ of the skipjack Katsuwonus pelamis. FAO Fish. Rept. 3: 1621-1631.

Halama, L. 1982. Morphometry of the olfactory organs of the rainbow trout (Salmo gairdneri Rich.). Acta Biol. Cracov. Seri. Zoologia 24: 105.

Hasler, A.D. 1957. Olfactory and gustatory senses of fishes. In The physiology of fishes. Vol. 2, (Ed. M.E. Brown), Academic Press, New York. pp. 187-209.

Johnson, H.E. and C.J.D. Brown 1962. Olfactory apparatus in the blackrock fish Sebastodes melanops. Copeia 4: 838-840.

Kapoor, A.S. and P.P. Ojha 1972. Studies on ventilation of the olfactory chambers of fishes with a critical revaluation of the role of accessory nasal sacs. Arch. Biol. (Liege) 83: 167-178.

Kapoor, A.S. and P.P. Ojha 1973a. The olfactory apparatus in the flatfish Cynoglossus oligolepis. Trans. Amer. micr. Soc. 92(2): 298-304.

Kapoor, A.S. and P.P. Ojha 1973b. Functional anatomy of the nose and accessory nasal sacs in the teleost Channa punctatus. Acta. anat. 84: 96105.

Kleerkoper, H. 1969. Olfaction in fishes. Indiana University Press, Bloomington and London. 
Kyle, H.M. 1899. On the presence of nasal secretory sacs and a nasopharyngeal communication in teleosts with special reference to Cynoglossus semilaevis. Zool. J. Linn. Soc. 27: 541-556.

Nordeny, H. 1971. Is the local orientation of anadromous fishes determined by pheromones? Nature (Lond.) 233: 411413.

Ojha, P.P. and A.S. Kapoor 1973. The anatomy of the olfactory organs in the hill stream fish Glyptothorax telchitta (Ham.) with a note on its relationship with the mode of life of the fish. Zoologica Poloniae 22(4): 287-295.

Ojha, P.P. and A.S. Kapoor 1974. Structure and function of the olfactory organs in the fish Sisor rhabdophorus (Ham.). Acta. anat. 87: 124-130.

Parker, G.H.O. 1922. Smell, taste and the allied senses in the vertebrates. Monogr. Exper. Biol., D.B. Lippincelf, Philadelphia.

Pfeiffer, W. 1963. The morphology of the olfactory organ of the Pacific salmon (Oncorhynchus). Can. J. Zool. 41: 1233-1236.

Pfeiffer, W. 1964. The morphology of the olfactory organ of Hoplopagrus guentheri Gill. Can. J. Zool. 42: 235237.

Pfeiffer, W. 1965. The size of the olfactory organ in the burbot Lota lota L. Can. J. Zool. 43: 223-224.
Rana, A.K. 1980. Morphometric and cytochemical studies on the olfactory organs of certain fresh water fishes of India. T.M. Bhagalpur Univ., Bhagalpur, India (Ph.D. Thesis).

Rana, A.K., J. Ojha and J.S. Datta Munshi, (1978): Morphometrics of the olfactory rosette in relation to body weight in a fresh water murrel Channa punctatus (Bloch), Arch. Biol. (Bruxelles) 89: 403417.

Rana, A.K., J. Ojha and J.S. Datta Munshi 1980. Morphometrics of the olfactory rosette in relation to body weight in a fresh water murrel Channa gachua (Ham.). Ind. Biol. Jour. 2(1): 5-13.

Singh, S.P. 1967. Studies on the olfactory organs of certain fresh water teleost. Part 1. Morphology and anatomy. Ind. J. Zool. 8(2): 41-70.

Sinha, R.K. 1981. Studies on the olfactory organs of certain fresh water Indian teleosts. Magadh University, BodhGaya, India. (Ph.D. Thesis)

Sinha, R.K. 1989. Morphology and anatomy of the olfactory organs of the marine fish Thynus thunnina (cuv. and val.).In Proc. $76^{\text {th }}$ session of Ind. Sc. Cong., pp. 7.

Teichmann, H. 1954. Vergleichende untersuchungen an der Nase der Fische. Z. Morph. Okol. Tiere 43: 171-212.

Wunder, W. 1957. Die sinnesorgane der Fische. Allgem. Fischeree Zeitung 82: 1-24. 